\title{
Hard cases of third readings in terms of the Standard Solution ${ }^{1}$ Petr KUSLIY - University of Massachusetts Amherst \\ Ekaterina VOSTRIKOVA - University of Massachusetts Amherst
}

\begin{abstract}
Schwager (2011) and Sudo (2014) argued that there are cases of the so-called third readings of attitude reports, initially discovered by Fodor (1970), that cannot be accounted for in terms of a theory of indexed world variables (Percus, 2000), which is often referred to as the Standard Solution. More complicated alternatives to the Standard Solution have been recently formulated in the literature in a number of papers. We argue that all the seemingly problematic cases can be naturally accounted for in terms of the Standard Solution, if we take into account the existence of previously unrecognized elided material in these reports.
\end{abstract}

Keywords: attitude reports, non-specific transparent, hard cases, Standard Solution.

\section{Introduction}

In this paper, we discuss so-called third readings of indefinites in attitude reports, originally discovered by Fodor (1970). Third readings exist in addition to the familiar de re and de dicto readings and combine some properties of both. The theory that is known in the literature as the Standard Solution straightforwardly accounts for third readings by introducing a mechanism of indexed world variables into the syntax. The hard cases for the Standard Solution are the challenging examples that were proposed by and discussed in Schwager (2011) and Sudo (2014). These authors argued that the hard cases called for more complicated alternatives to the Standard Solution.

Alternative theories have been formulated in terms of evaluating a property in the metaphysically closest worlds where the property is not empty (Schwager, 2011), substitution of contextually equivalent functions (Sudo, 2014), generalized concept generators (Baron, 2015), and a pragmatic account that assumes a modification of the context set of the conversation (Tiskin, 2016).

We will argue that all the seemingly problematic cases can be naturally accounted for in terms of the Standard Solution. We make an observation that in all of the problematic beliefreports the structure is more complex than was previously assumed. In a number of cases, there is elided material that needs to be reconstructed. We show how reconstructing this material allows the Standard Solution to deal with the problematic cases. We thus intend to show that more complicated treatments are not required to account for third readings.

The discussion in this paper will proceed as follows. In Section 2, we briefly introduce third readings. In Section 3, we discuss the Standard Solution and how it captures these readings. Section 4 presents two illustrative challenging cases from Schwager (2011). In Section 5, we demonstrate how those cases can be naturally accounted for in terms of the Standard Solution

\footnotetext{
${ }^{1}$ We would like to thank Seth Cable and Barbara Partee for all their help and the audiences at "Sinn und Bedeutung-22" (Berlin/Potsdam 7-10.09.2017) and UMass Semantics Workshop (20.09.2017, UMass Amherst) for their critical discussion and suggestions. All errors are our own.
} 
given some independently motivated assumptions. In Section 6, we go over other known hard cases and show that our proposal can be successfully extended to those cases as well.

\section{Third readings of attitude reports}

Third readings of attitude reports are known to be a middle case between the more familiar de $r e$ and de dicto readings. Third readings combine some properties of a de re and some properties of a de dicto interpretation but cannot be reduced to either. Consider a simple example in (1).

(1) Mary wants to buy an expensive dress.

According to a de re interpretation of (1), there is a particular expensive dress and Mary wants to buy that dress. Mary is specific about the object that she wants to buy, but it is from the speaker's perspective that the object is an expensive dress. Mary might not be aware of its price or even that it is a dress. She might describe this object to herself differently.

The de re interpretation can be expressed in terms of an indefinite taking scope over the intensional verb (the idea goes back to (Russell, 1905). At LF, the indefinite an expensive dress undergoes quantifier raising as illustrated in (2) in the notation of Heim and Kratzer (1998).

(2) [ [an expensive dress] [1 [ Mary [ wants [PRO to buy $\left.\left.\left.\left.\left.\mathrm{t}_{1}\right]\right]\right]\right]\right]$

Interpreting the indefinite in this position has two major effects on the interpretation of (1). The existential quantifier introduced by the indefinite scopes above the universal quantifier introduced by the attitude verb. This makes the de re reading of (1) specific (Mary wants to buy a concrete object). The descriptive content of the indefinite is evaluated in the actual world (and not in the worlds compatible with Mary's desires). This makes the de re reading transparent (the object that Mary wants to buy is an expensive dress from the speaker's perspective). De re readings of attitude reports are, thus, also known as specific transparent.

According to a de dicto interpretation, Mary wants to buy some expensive dress but she does not have a specific dress in mind.

Under the scope theory, this reading is expressed by interpreting the indefinite below the attitude verb (allowing it to raise only locally to avoid a type mismatch), as illustrated in (3):

(3) [Mary [wants [ [an expensive dress] [1 [PRO to buy $\left.\left.\left.\left.\left.\mathrm{t}_{1}\right]\right]\right]\right]\right]$

The de dicto reading is known as non-specific opaque (because the indefinite scopes below the attitude verb and its descriptive content is interpreted in Mary's desire alternatives).

This sentence also has a third reading that is non-specific transparent: Mary does not have a concrete dress in mind and is choosing among what happens to be expensive dresses from the point of view of the speaker (but not necessarily in Mary's desire alternatives). The third reading thus shares the transparency of a de re interpretation (the objects that Mary is 
choosing from are judged as expensive dresses from the speaker's perspective) and the nonspecificity of a de dicto interpretation (Mary does not want any particular dress).

Expressing this reading in terms of the scope theory is challenging and requires additional assumptions (see (Keshet, 2008; 2011)).

\section{The Standard Solution}

The third reading of the attitude report in (1) can be successfully modeled within a theory that is now known as the Standard Solution (Percus, 2000).

The two key ingredients of this theory are indexed world variables and lambda abstractors that bind those variables in the syntax at each clausal level. In this system, each predicate including the ones that are inside DPs comes with its own word variable. The world variable that a predicate inside a DP carries does not have to have the same index as the main predicate of the clause and therefore can be bound by a different lambda abstractor. The LFs of sentences containing propositional attitudes, like the one in (1), have two lambda abstractors: the matrix one and the embedded one.

A possible LF for (1) is given in (4) and the resulting interpretation of this LF is given in (5).

(4) LF: $\left[\lambda \mathrm{w}_{1}\right.$ Mary wants- $\mathrm{w}_{1}\left[\lambda \mathrm{w}_{2}\left[\right.\right.$ an [expensive dress- $\left.\left.\mathrm{w}_{1}\right]\right]\left[1\right.$ PRO to buy- $\left.\left.\left.\mathrm{w}_{2} \mathrm{t}_{1}\right]\right]\right]$

(5) $\|(2)\|^{\mathrm{g}}(\mathrm{w})=1$ iff

$\forall \mathrm{w}^{\prime} \in$ Desire-Alt(Mary,w): $\exists \mathrm{x}\left(\mathrm{x}\right.$ is expensive dress in $\mathrm{w} \&$ Mary buys $\mathrm{x}$ in $\left.\mathrm{w}^{\prime}\right)$

What we observe in (4) is that the DP "an expensive dress" stays within the embedded clause. The world variable that comes with the predicate "expensive dress" carries an index that is different from the index of the world variable on the main verb of the embedded clause and is bound by the matrix lambda abstractor. Thus, the existential quantifier is interpreted in the scope of the intensional verb, which accounts for the fact that Mary is not specific in her desire, but the predicate "expensive dress" is interpreted with respect to the actual world and not in Mary's doxastic alternatives, which accounts for the fact that she does not know that those dresses are expensive.

\section{Two counterexamples to the Standard theory (Schwager, 2011)}

In this section, we will discuss two illustrative examples from Schwager (2011).

\subsection{Malte's jacket}

One seemingly problematic example discussed by Schwager (2011) is given in (6).

(6) Adrian wants to buy a jacket like Malte's. 
The context that makes this example problematic is as follows.

Context: Malte has a green Bench jacket. The attitude holder, Adrian, also wants a green Bench jacket but he does not know what kind of jacket Malte has.

Native speakers of English report that (6) is acceptable in this context.

The reading that (6) has in the context given above is a third reading: Adrian is not specific and what he wants to buy is described from the point of view of the speaker.

If third readings are generated by evaluating an embedded predicate with respect to the actual world, then the challenge here is that it is not clear what predicate we could evaluate with respect to the actual world to capture this judgment.

Since Adrian does not know what kind of jacket Malte has, evaluating "jacket like Malte's" with respect to Adrian's doxastic alternatives does not give us the right interpretation. However, as (Schwager, 2011) points out, evaluating this predicate with respect to the actual word does not help us either. In order to see this, let us consider the LF in (7), where the world variable on the predicate "jacket like Malte's" is bound by the matrix lambda abstractor.

(7) $\left[\lambda \mathrm{w}_{1}\right.$ Adrian wants- $\mathrm{w}_{1}\left[\lambda \mathrm{w}_{2}\right.$ PRO to buy- $\mathrm{w}_{2}$ a [jacket like Malte's- $\left.\left.\left.\mathrm{w}_{1}\right]\right]\right]$

Interpreting this LF results in the truth-conditions given in (8).

(8) $\|(7)\|^{\mathrm{g}}(\mathrm{w})=1$ iff

$$
\begin{aligned}
& \forall \mathrm{w}^{\prime} \in \text { Desire-Alt(Adrian,w): } \\
& \quad \exists x\left(\mathrm{x} \text { is a jacket like Malte's in w \& Adrian buys } \mathrm{x} \text { in } \mathrm{w}^{\prime}\right)
\end{aligned}
$$

The problem that Schwager notices here is that (8) predicts that, in his desire alternatives, Adrian has to choose from the actual green Bench jackets (under the reasonable assumption that "like" stands for "being of the same type and color"). This does not seem to be right. Since colors are not essential properties of objects, a jacket can have one color in one world and a different color in another world. The truth conditions in (8) predict that Adrian in his doxastic alternatives will buy a red Bench jacket as long as it is a green Bench jacket in the actual world. Thus, in the case of example (8), the Standard Solution seems to overgenerate. On the other hand, intuitively, if some jacket happens to be a green Bench jacket in one of Adrian's bouletic alternatives but is a red Bench jacket in the actual world, Adrian should be able to buy this jacket in that alternative world. This, however, is not captured by the truthconditions in (8). According to (8), Adrian, in his bouletic alternatives, has to be buying one of those jackets that happen to be green Bench jackets in the actual world. Thus, the Standard Solution seems to undergenerate as well as overgenerate at the same time.

We can conclude that the predicted interpretation of the LF given in (7) does not reflect the fact that the sentence in (6) is intuitively true in the given context. 


\subsection{Burj Khalifa}

Another difficult case discussed by Schwager is presented by the example in (9).

(9) Mary wants to buy a building with 192 floors.

The context that brings to light the problem with (9) is as follows.

Context: Mary is looking at Burj Khalifa, the building in Dubai that has 191 floors. No other currently existing building has more floors that that number. However, Mary does not know this. She also does not know how many floors Burj Khalifa has. She says, 'Wow, I want to buy a building that's even one floor higher!'

According to Schwager (2011), there are two possible LFs that the Standard Solution can give to this sentence. In the one given in (10), the DP "building with 192 floors" comes with the world variable that is bound by the embedded lambda abstractor. Schwager rejects this LF because Mary does not know the height of the building. The other option is the LF given in (11), where the world variable on the predicate "building with 192 floors" is bound by the matrix lambda abstractor. This ensures that the predicate is evaluated transparently (with respect to the actual world).

(10) $\left[\lambda \mathrm{w}_{1}\right.$ Mary wants- $\mathrm{w}_{1}\left[\lambda \mathrm{w}_{2}\right.$ PRO to buy- $\mathrm{w}_{2}$ a [building with 192 floors- $\left.\left.\mathrm{w}_{2}\right]\right]$

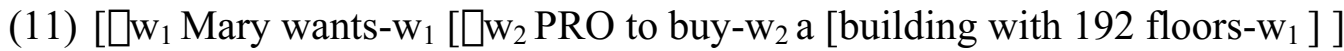

The problem with the LF in (11) is that the predicate "building with 192 floors" has an empty set as its extension in the actual world (because no such building exists in the actual world). This LF will get the interpretation shown in (12).

$$
\begin{aligned}
(12)\|(11)\|^{\mathrm{g}}(\mathrm{w})=1 \text { iff } & \\
\forall \mathrm{w}^{\prime} \in & \text { Desire-Alt(Mary,w): } \\
& \exists \mathrm{x}\left(\mathrm{x} \text { a building with } 192 \text { floors in w \& Mary buys } \mathrm{x} \text { in } \mathrm{w}^{\prime}\right)
\end{aligned}
$$

Since there are no worlds where the existential claim holds true, the entire sentence is true only if the set of Mary's desire-alternatives is empty. (This is due to the properties of the universal quantifier that is involved in the interpretation of the intensional verb "want" that yields true if its restrictor is empty).

\subsection{Schwager's (2011) proposal}

Schwager (2011) argues that the challenging cases discussed above require us to abandon the Standard Solution. She suggests that the problematic cases can be accounted for if we adopt the Replacement Principle in (13).

(13) Replacement Principle: For the sake of reporting an attitude, a property that is involved in the content of the attitude that is to be reported (the reported property) can be 
replaced by a different property (the reporting property) as long as the reported property is a subset of the reporting property at all relevant worlds.

An important part of this proposal is the notion of a relevant world. Schwager (2011) suggests that the relevant worlds are those which are closest to the actual world and in which the reporting property is not empty.

This principle accounts for the Malte's jacket example because in every relevant world (i.e. the closest worlds in which there are jackets like Malte's-green Bench jackets-and Malte has the same jacket as he does in the actual world) the reported property (being a green Bench jacket), is a subset of the reporting property (being a jacket like Malte's).

The Burj Khalifa example is accounted for in a similar way. Even though the property of being a building that is one floor higher than Burj Khalifa is empty in the actual world, we are looking only at those worlds where there are 192-floor buildings and Burj Khalifa has 191 floors as it does in the actual world. So, in each of her bouletic alternatives, Mary ends up buying one of the 192-floor buildings from the closest worlds and the fact that the predicate 192-floor building is empty in the actual world is no longer relevant.

Even though Schwager's analysis correctly captures the problematic cases, it may raise questions regarding its independent motivation. Invoking the notion of closest worlds only for the purposes of evaluating a predicate seems to be a technical tool that gives us the correct truth conditions but has no other relevant use. It is not also clear why appealing to these worlds gives us the right truth conditions. Deriving those readings from mechanisms that are more familiar and better understood would be preferable.

\section{Analysis}

In what follows, we argue that all the hard cases can be accounted for in terms of the Standard Solution. We employ one general strategy. In each case, we observe that the relevant attitude report contains an elided predicate or is equivalent to a report that is directly picked up from the context and contains an elided predicate. We reconstruct the predicate, allow it to be evaluated in the actual world in the spirit of Percus (2000), and derive the third reading.

\subsection{Predicting the Malte's jacket example}

We follow Schwager (2011) and assume that being a jacket like Malte's means being a jacket of the same brand and color. This suggests that we are dealing with an equative construction (Heim, 2000; Bhatt and Pancheva, 2004) that, like other comparative constructions, assumes comparative deletion (Bresnan, 1973; Lechner, 2014). For the purposes of this demonstration, we do not commit ourselves to any particular syntax associated with a like-comparative ${ }^{2}$. We only require that there be some kind of NP-ellipsis (or N'-ellipsis (Jackendoff, 1971)) in the relevant attitude report, as suggested in (14):

\footnotetext{
${ }^{2}$ But see (Matushansky and Ruys, 2007) for a discussion of the semantics of same, which is similar to the construction considered here.
} 
(14) Adrian wants to buy a jacket like Malte's jacket.

We assume that the elided NP, like all other NPs, comes with a world variable that can be bound by a matrix lambda operator. This makes (15) a possible LF for (14):

(15) $\left[\lambda \mathrm{w}_{1}\right.$ Adrian wants- $\mathrm{w}_{1}\left[\lambda \mathrm{w}_{2}\left[\mathrm{a}\left[\mathrm{jacket}-\mathrm{w}_{2}\right.\right.\right.$ like Malte's jacket- $\left.\left.\mathrm{w}_{4}\right]\right]\left[3\left[\mathrm{PRO}\right.\right.$ to buy- $\mathrm{w}_{2}$ $\left.\left.\left.\left.\mathrm{t}_{3}\right]\right]\right]\right]$

In (15), the indefinite undergoes quantifier raising just to avoid a type mismatch and still remains within the scope of the attitude predicate.

We argue that (15) is an accurate report of Malte's desire in the context provided for this example. Since Malte's jacket in the actual world is a green Bench jacket, then being a jacket like Malte's jacket in the actual world is being a green Bench jacket in any world. And, whoever wants to buy a jacket like Malte's jacket in the actual world wants to buy a green Bench jacket.

To put it differently, (16) is equivalent to (15):

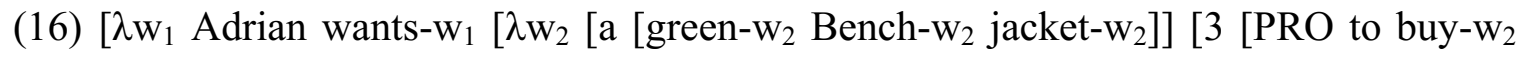
$\left.\left.\left.\left.\mathrm{t}_{3}\right]\right]\right]\right]$

The embedded clauses in (15) and (16), reproduced in (17) and (18), respectively, denote exactly the same set of possible worlds (assuming that $\mathrm{w}_{1}$ is the actual world):

(17) $\left[\lambda \mathrm{w}_{2}\left[\mathrm{a}\left[\mathrm{jacket}-\mathrm{w}_{2}\right.\right.\right.$ like- $\mathrm{w}_{2}$ Malte's jacket-w $\left.\left.\mathrm{w}_{4}\right]\right]\left[3\left[\mathrm{PRO}\right.\right.$ to buy- $\left.\left.\left.\mathrm{w}_{2} \mathrm{t}_{3}\right]\right]\right]$

(18) $\left[\lambda \mathrm{w}_{2}\left[\mathrm{a}\left[\right.\right.\right.$ green-w $\mathrm{w}_{2}$ Bench- $\mathrm{w}_{2}$ jacket- $\left.\left.\mathrm{w}_{2}\right]\right]\left[3\left[\mathrm{PRO}\right.\right.$ to buy- $\left.\left.\left.\mathrm{w}_{2} \mathrm{t}_{3}\right]\right]\right]$

And, since (16), as we said, straightforwardly describes the context, so does (15).

This analysis assumes that a cross-world comparison of predicates is possible. This assumption is independently motivated by the existence of reports like "I thought that your yacht is longer than it is" discussed in Russell (1905). Here, the degree to which the yacht is long in the attitude holder's doxastic alternatives is compared to the degree to which the yacht is long in the actual world.

\subsection{Predicting the Burj Khalifa example}

We apply similar reasoning to (19), repeated below:

(19) Mary wants to buy a building with 192 floors.

Context: Mary is looking at the Burj Khalifa, which has 191 floors. No other currently existing building has more floors. Mary doesn't know this. She also doesn't know how many 
floors Burj Khalifa has. She says, 'Wow, I want to buy a building that's even one floor higher!'

It seems uncontroversial that (20) correctly describes Mary's desire because it represents the information that the speaker picks up directly from the context:

(20) Mary wants to buy a building that is one floor higher than Burj Khalifa.

We again assume ellipsis inside the embedded comparative construction. We reconstruct the elided material together with the world variable. We bind the variable by the matrix abstractor as illustrated in (21):

(21) $\left[\lambda \mathrm{w}_{1}\right.$ Mary wants- $\mathrm{w}_{1}\left[\lambda \mathrm{w}_{2}\right.$ [a building- $\mathrm{w}_{2}$ that is one floor higher than Burj Khalifa is high- $\left.w_{4}\right]\left[3\left[\mathrm{PRO}\right.\right.$ to buy- $\left.\left.\left.\left.\mathrm{w}_{2} \mathrm{t}_{3}\right]\right]\right]\right]$

As for the problematic (19), we provide it with the LF in (22):

(22) $\left[\lambda \mathrm{w}_{1}\right.$ Mary wants- $\mathrm{w}_{1}\left[\lambda \mathrm{w}_{2}\right.$ [a building- $\mathrm{w}_{2}$ that has 192 floors- $\left.\mathrm{w}_{2}\right]\left[3\left[\mathrm{PRO}\right.\right.$ to buy- $\mathrm{w}_{2}$ $\left.\left.\left.\left.\mathrm{t}_{3}\right]\right]\right]\right]$

We argue that (21) and (22) are equivalent because their embedded clauses denote the same set of possible worlds.

To put it differently, in any world it is the case that buying a building with 192 floors is buying a building that is one floor higher than Burj Khalifa is in the actual world.

We are aware of the fact that we are proposing a de dicto LF in (12) for a case in which Mary would not herself describe her desire in terms of buying a 192-floor building. Our proposal here assumes that as long as she can desire to buy a building that is one floor higher than the actual Burj Khalifa, the structure in (22) truly and objectively describes that desire.

\subsection{The Intersective Predicate Generalization is not violated}

Keshet (2008) introduces a restriction on the indexation of world variables known as The Intersective Predicate Generalization. According to this restriction, the world variables on intersecting predicates cannot carry different indices. Our analysis does not violate this restriction because the elided predicate that we reconstruct with a world variable bound by the matrix abstract does not intersect with a predicate in which the index on the world variable is bound locally.

In the Malte's jacket example, the elided NP is inside a DP. In the Burj Khalifa example the elided predicate is a subconstituent inside a comparative construction and does not intersect with any other predicate either.

\section{Other cases}


In this section, we explore two remaining difficult cases discussed in the literature and show that the line of argumentation proposed in Section 5 can be successfully extended to those cases as well.

\subsection{The Curfew Example}

The first example (23) is Schwager's (2011) adaptation of an example from Fodor (1970).

(23) The reporter wants to interview someone who broke the curfew.

The context that makes this example interesting is as follows.

Context: A reporter comes to a town $\mathrm{N}$ to interview people who could possibly witness a crime that happened after 6 p.m. She wants to talk to someone who was outside after 6 p.m. Unbeknownst to her, there is a curfew in $\mathrm{N}$ that starts at 6 p.m. and no one was out at that time.

If we try to give this sentence the LF in (24), where the world variable inside the DP someone who broke the curfew is bound by the matrix lambda abstractor, we will run into the same problem as the one observed in the Burj Khalifa example: the set of people who broke the curfew is empty in the actual world.

(24) $\left[\lambda \mathrm{w}_{1}\right.$ The reporter- $\mathrm{w}_{1}$ wants- $\mathrm{w}_{1}\left[\lambda \mathrm{w}_{2}\right.$ PRO to interview- $\mathrm{w}_{2}$ some [one who broke- $\mathrm{w}_{1}$ the curfew- $\left.\left.\left.\mathrm{w}_{1}\right]\right]\right]$

As in all other cases, we observe that there are several predicates that can potentially carry world variables in this sentence. In particular, there is a DP inside the predicate who broke the curfew and the predicate inside this DP can carry a different world variable than the one on break. The LF we propose for (23) is given in (25).

(25) $\left[\lambda \mathrm{w}_{1}\right.$ The reporter- $\mathrm{w}_{1}$ wants- $\mathrm{w}_{1}\left[\lambda \mathrm{w}_{2}\right.$ PRO to interview- $\mathrm{w}_{2}$ some [one who broke- $\mathrm{w}_{2}$ the curfew- $\left.\left.\left.\mathrm{w}_{1}\right]\right]\right]$

The report that is directly suggested by the context is given in (26) and its LF is shown in (27).

(26) The reporter wants to interview someone who was outside after 6 p.m.

(27) $\left[\lambda \mathrm{w}_{1}\right.$ The reporter- $\mathrm{w}_{1}$ wants- $\mathrm{w}_{1}\left[\lambda \mathrm{w}_{2}\right.$ PRO to interview- $\mathrm{w}_{2}$ some [one who was outside after 6 p.m.- $\left.\mathrm{w}_{2}\right]$ ] ]

Since the interpretations of (28) and (29) below pick out the same set of worlds (assuming that $\mathrm{w}_{0}$ denotes the actual world), they are interchangeable in intensional contexts.

(28) $\left[\lambda \mathrm{w}_{2}\right.$ PRO to interview- $\mathrm{w}_{2}$ some [one who broke- $\mathrm{w}_{2}$ the curfew-w $\left.\mathrm{w}_{0}\right]$ 
(29) $\left[\lambda \mathrm{w}_{2}\right.$ PRO to interview- $\mathrm{w}_{2}$ some [one who was outside after 6 p.m. $\left.\left.\mathrm{w}_{2}\right]\right]$

Thus, the LFs in (25) and in (27) have equivalent interpretation and (23) can be truly used in the context.

If this analysis is on the right track, we need to accept the possibility that a law of one possible world can be broken (violated) in a different world. Breaking is understood here not as intentional violation, but merely as doing something that is not compatible with the law.

6.2 The same denomination example (Sudo, 2014)

The last example of a difficult case for the Standard Solution that we will discuss in this paper is from Sudo (2014). The example is given in (30).

(30) Mary thinks that Sue is Catholic.

This sentence is judged to be true in the following context.

Context: Mary is an atheist and quite ignorant in questions of religion. She does not differentiate between various branches of Christianity. She heard that our religious friend John started going out with a girl named Sue. Mary decided that Sue has to belong to the same denomination as John, but she does not know which. The speaker, unlike Mary, knows that John is Catholic.

The problem here is that Mary does not know that Sue is Catholic. Giving the predicate Catholic a world variable bound by the embedded matrix abstractor will not do. On the other hand, providing Catholic with a world variable bound by the abstractor of the main clause will result in the structure that violates Generalization X (Percus, 2000). According to this generalization, a world variable that a main predicate of a sentence carries has to be bound by the nearest lambda abstractor. The example from Percus (2000) that supports this generalization is given in (31).

(31) Mary thinks that my brother is Canadian.

If (31) could have an LF as the one given in (32), this sentence would be judged as true in a scenario where there is a person who Mary thinks is my brother (perhaps mistakenly) and who is a Canadian in the actual world, even if Mary does not know that. This sentence does not have this reading.

(32) $\left[\lambda \mathrm{w}_{2}\right.$ Mary thinks- $\mathrm{w}_{2}$ that $\left[\lambda \mathrm{w}_{1}\right.$ my brother- $\mathrm{w}_{1}$ is Canadian- $\left.\left.\mathrm{w}_{2}\right]\right]$

Based on examples like (31), Percus concludes that there is a general restriction on binding the world variable on the main predicate of a sentence by a long distance lambda abstractor.

If the Generalization $\mathrm{X}$ is correct, the fact that (30) is acceptable in the described scenario is puzzling. 
The solution proposed by Sudo (2014), like Schwager's solution, appeals to a replacement principle. He suggests that a predicate (say, the following predicate: [ $\lambda \mathrm{w} . \lambda \mathrm{x} . \mathrm{x}$ and John belong to the same denomination in w]) can be replaced by another predicated in a beliefreport as long as they are a contextually equivalent. The solution we propose here does not require any special replacement principles. It involves the following steps. First, we recover the belief-report that is picked up directly from the context (33).

(33) Mary thinks that Sue belongs to the same denomination as John.

Then we reconstruct the elided material and we get the LF given in (34).

(34) $\left[\lambda w_{1}\right.$ Mary thinks- $w_{1}\left[\lambda w_{2}\right.$ Sue belongs- $w_{2}$ to the same denomination- $w_{2}$ as John belongs- $\left.w_{4} t \theta\right]$ ]

We observe that (35) and (36) denote the same proposition. This is because in every possible world having the same denomination as the denomination that John has in the actual world is being Catholic.

(35) $\left[\lambda \mathrm{w}_{2}\right.$ Sue belongs- $\mathrm{w}_{2}$ to the same denomination- $\mathrm{w}_{2}$ as John belongs- $\mathrm{w}_{\theta}$ to

(36) $\left[\lambda \mathrm{w}_{2}\right.$ Sue is Catholic- $\left.\mathrm{w}_{2}\right]$

This means that we can substitute (36) for (35) and the report has to stay true. If so, then (30) must be true if it is understood to have the LF in (37):

(37) $\left[\lambda \mathrm{w}_{1}\right.$ Mary thinks- $\mathrm{w}_{1}\left[\lambda \mathrm{w}_{2}\right.$ Sue is Catholic- $\left.\left.\mathrm{w}_{2}\right]\right]$

Our solution to this puzzle does not violate Generalization X, because the main predicate of the sentence "Catholic" is interpreted de dicto.

\section{Conclusion}

In this paper, we considered the challenging cases of third readings of indefinites in attitude reports. We argued that all of the seemingly problematic examples can be naturally accounted for by the Standard Solution. In some of the cases, it was enough to reconstruct the elided material. In other cases, we had to consider a report that is directly suggested by the context, reconstruct the elided material and observe that the report that is considered to be problematic is semantically equivalent to it.

In our analysis, we used a principle of substitutivity that allowed us to replace one report with another. We believe that the principle we used is essentially different from the ones suggested in Schwager (2011) and Sudo (2014). The principle of substitutivity that we made appeal to is not a part of the theory that we suggest but is a metatheoretic principle-principle of compositionality-that is assumed by everyone doing compositional semantics.

\section{Appendix}


Of all the examples discussed above, the Standard theory applies in the most straightforward way to the case of Buyer's intensions and the Curfew example. In both of those cases, the relevant report contains a predicate that is evaluated with respect to the actual world. We repeat the two sentences from the earlier sections in (1) and (3) together with their LFs below.

(1) Adrian wants to buy a jacket like Malte's.

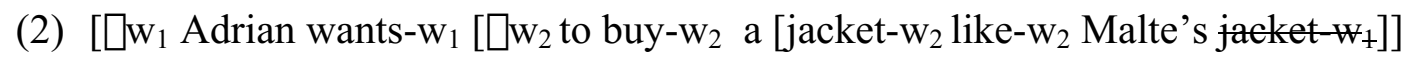

(3) The reporter wants to interview someone who broke the curfew.

(4) $\left[\lambda w_{1}\right.$ The reporter wants- $w_{1}\left[\lambda w_{2}\right.$ PRO to interview- $w_{2}$ some [one who broke- $w_{2}$ the curfew-w $]]]$

The more controversial cases are the cases of Burj Khalifa and Sue's Catholicism. For the case of Burj Khalifa, repeated in (5), we proposed the LF in (6):

(5) Mary wants to buy a building that has 192 floors.

(6) $\left[\lambda \mathrm{w}_{1}\right.$ Mary wants- $\mathrm{w}_{1}\left[\lambda \mathrm{w}_{2}\right.$ PRO to buy- $\mathrm{w}_{2}$ a building-w +2 that has 192 floors- $\left.\left.\mathrm{w}_{2}\right]\right]$

We observed that (6) was equivalent to (7), which was a possible LF for a report supported by the given context and provided in (8):

(7) $\left[\lambda \mathrm{w}_{1}\right.$ Mary wants- $\mathrm{w}_{1}\left[\lambda \mathrm{w}_{2}\right.$ PRO to buy- $\mathrm{w}_{2}$ a building $-\mathrm{w}_{2}$ that is one floor higher- $\mathrm{w}_{2}$ than Burj Khalifa is high- $\left.\left.w_{4}\right]\right]$

(8) Mary wants to buy a building that is one floor higher than Burj Khalifa.

The issue that someone might find bothersome here can be described as follows. In (6), the indefinite is interpreted under the intensional verb and the predicate inside this indefinite is bound by the embedded lambda operator. So, under this analysis, (5) is a pure de dicto report.

However, the context was set up in such a way that Mary does not know the height of Burj Khalifa and she would not accept (5). Moreover, double vision scenarios similar to the famous examples known from (Quine, 1956) can be constructed in this case. For example, it is conceivable that in a different context when she is shown a project of a building that has 192 floors, the same person Mary says, "I don't want to buy a building that is this high".

Similarly, in the example with Sue's Catholicism, we proposed the LF given in (9) for the sentence in (10):

(9) $\left[\lambda \mathrm{w}_{1}\right.$ Mary thinks- $\mathrm{w}_{1}\left[\lambda \mathrm{w}_{2}\right.$ Sue is Catholic- $\left.\left.\mathrm{w}_{2}\right]\right]$

(10) Mary thinks that Sue is Catholic. 
Again, we observed that that its interpretation is equivalent to that of (11) which is a possible LF for the report directly suggested by the context and given in (12):

(11) $\left[\lambda w_{1}\right.$ Mary thinks- $w_{1}\left[\lambda w_{2}\right.$ Sue belongs- $w_{2}$ to the same denomination- $w_{2}$ as John belongs to- $\left.\mathrm{w}_{1}\right]$ ]

(12) Mary thinks Sue belongs to the same denomination as John.

However, like in the previous case, (9) does not contain any predicate in the embedded clause that is evaluated transparently. This is a de dicto report that Mary herself would not accept.

And, even for the Curfew example, which does not require this kind of unusual de dicto analysis, it might still be argued that, in our proposed analysis, the predicate "break" is evaluated with respect to the worlds of the reporter even though the reporter does not know about the existence of a restriction that is being broken.

We explored the account that the Standard Solution could provide for all these cases. The abovementioned worrisome aspects of the analysis are the price that we have to pay if we want to apply the Standard Solution to all of the problematic cases. Yet, it is possible that the analysis in terms of the third readings might not be applicable to these last three cases in the first place.

Schwager (2011) makes an observation that all the hard cases except one, the Malte's jacket case, can be handled in terms of the de qualitate analysis. In a nutshell, the analysis in terms of de qualitate would require interpreting the property in the restrictor of the indefinite ("jacket like Malte's") in the transparent position. The sentence is predicted to be true if there is a concept such that in the actual world it picks the property of being a jacket like Malte's (the property given in (13)) and in the worlds of Adrian's doxastic alternatives picks a property of being a green bench jacket. This concept can be defined technically, however, it cannot reflect the way the property is cognitively given to the attitude holder. The scenario is set up in such a way that the property "be a jacket like Malte's" is not given to the attitude holder under any guise, Adrian does not have any cognitive contact with it.

(13) $[\lambda w . \lambda x . x$ is jacket-like-Malte's in $w]$

In this paper, we have shown that there is elided material in this report and when this material is taken into account, this example is no longer a hard case but is just another illustration of a third reading in a classical sense.

As for the remaining cases, it might, indeed, be quite possible to account for them in terms of a de qualitate analysis (Cresswell and Von Stechow, 1982) or in terms of generalized concept generators (Baron, 2015). However, we are not convinced that de qualitate analysis is necessary here. In the remaining part of this Appendix, we would like to outline an 
alternative $d e r e^{3}$ analysis of the three cases. We believe that, in each of the cases it is possible to find something that is not a property that can be interpreted as a res of a de re construal.

We suggest that, in the Burj Khalifa case, it is 192 that is interpreted de re. A possible LF for this example is given in (14). Following Percus and Sauerland (2003) and Charlow and Sharvit (2014), a variable $G$ of the concept generator type is merged as a sister to 192 and is bound by the lambda abstractor at the edge of the embedded clause. A concept generator takes a number and returns a concept - a function from a world to a number. Quantification over concept generators is introduced by the intensional verb and it is relating the concept generator and the attitude holder. The resulting interpretation is given in (15).

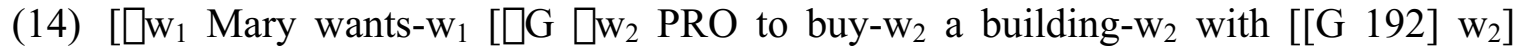
floors- $\left.\mathrm{w}_{2}\right]$ ]

(15) $\|(14)\|^{\mathrm{g}}(\mathrm{w})=1$ iff $\exists \mathrm{G}$ such that $\mathrm{G}$ is a concept generator for Mary in $\mathrm{w} \& \forall \mathrm{w}^{\prime} \in$ Desire-Alt (Mary, w): $\exists y . y$ is a building in w' and y has G(192)(w') floors in w' and Mary is buying $\mathrm{y}$ in $\mathrm{w}$ '.

One possible concept generator will map the number 192 to the concept given in (16).

(16) $\left[\lambda w^{\prime}\right.$. the number of floors in the building Mary is looking at in $\left.w^{\prime}+1\right]$

The belief-report in case of Sue's Catholicism can be represented as a de re attitude with respect to Catholicism under the assumption that the adjective "Catholic" can be further decomposed into two parts, one of which stands for "Catholicism" and the other one for "be the follower of'. The truth conditions that (10) will be assigned in that case are given in (17):

(17) $\|(10)\|^{\mathrm{g}}(\mathrm{w})=1$ iff $\exists \mathrm{G}$ such that $\mathrm{G}$ is a concept generator for Mary in $\mathrm{w}$ $\& \forall w^{\prime} \in \operatorname{Dox}($ Mary, w): Sue is a follower of G(Catholicism)(w')

A possible context generator in this case could be the one that maps "Catholicism" into the concept given in (18).

(18) $\left[\lambda w^{\prime}\right.$. the religion that John has in w']

As for the Curfew example, Schwager (2011) does not discuss it in much detail. She says, however, that a de re analysis is not applicable, if the true de dicto report is (19) and what is to be interpreted as a de re report is (20).

(19) The reporter wants to talk to someone who was outside after 6 p.m.

(20) The reporter wants to talk to someone who broke the curfew.

\footnotetext{
${ }^{3}$ De re in this appendix is understood as a de re construal interpretation. It is a different notion of de re than the one used in Section 2, where it simply referred to the fact that an indefinite took scope above the intensional verb.
} 
Under a de dicto interpretation, (19) asserts that the reporter interviews someone who was outside after 6 p.m. in each of her desire worlds. Under a de re interpretation of (20), only the speaker knows that 6 p.m. is the time of the curfew.

It is not immediately clear why a de re analysis would not be applicable in this case. Suppose the relevant concept is

(21) $\left[\lambda w^{\prime}\right.$. the boundary of 6 p.m. in w']

This concept maps any possible world to 6 p.m. in that world by default. However, in the actual world, the boundary of $6 \mathrm{p} . \mathrm{m}$. is identical to the boundary of the curfew, i.e. to the curfew itself. Therefore, breaking the 6 p.m. boundary (by being outside) in the actual world is breaking the curfew in the actual world.

We thus predict the following de re LF for (20):

(22) $\left[\lambda \mathrm{w}_{1}\right.$ The reporter- $\mathrm{w}_{1}$ wants- $\mathrm{w}_{1} \lambda \mathrm{G} \lambda \mathrm{w}_{2}$ PRO to interview- $\mathrm{w}_{2}$ someone who broke$\mathrm{w}_{2}\left[\mathrm{G}\left[\right.\right.$ the curfew-w $\left.\left.\left.\mathrm{w}_{1}\right] \mathrm{w}_{2}\right]\right]$

We conclude that if the ideas expressed here are on the right track, the so-called hard cases of third readings either can be straightforwardly accounted for in terms of the Standard Solution or they don't qualify for the analysis in terms of the Standard Solution to begin with but can be captured by a de re interpretation.

\section{References}

Baron, C. (2015). Generalized Concept Generators. A unified account of de re, de dicto, and "third reading" attitude ascriptions. In The Proceedings of NELS-46 (pp. 59-68).

Bhatt, R. and Pancheva, R. (2004). Late Merger of Degree Clauses. Linguistic Inquiry, 35(1), 1-45. https://doi.org/10.1162/002438904322793338

Charlow, S. and Sharvit, Y. (2014). Bound "de re" pronouns and the LFs of attitude reports. Semantics and Pragmatics, 7(3), 1-43. https://doi.org/10.3765/sp.7.3

Cresswell, M. J. and Stechow, A. Von. (1982). “ De Re” Belief Generalized. Linguistics and Philosophy, 5(4), 503-535.

Fodor, J. D. (1970). The linguistic description of opaque contexts. https://doi.org/10.4324/9781315880303

Heim, I. (2000). Degree Operators and Scope. Proceedings of SALT 10, Cornell University, (1), 40-64.

Heim, I. and Kratzer, A. (1998). Semantics in generative grammar. Oxford: Blackwell.

Jackendoff, R. S. (1971). Gapping and Related Rules. Linguistic Inquiry, 2(1), 21-35.

Keshet, E. (2008). Good Intensions : Paving Two Roads to a Theory of the De re/De dicto Distinction. MIT.

Keshet, E. (2011). Split Intensionality: a new theory of scope of de re and de dicto. Linguistics and Philosophy, 33, 251-283. https://doi.org/10.1007/s

Lewis, D. (1979). Attitudes De Dicto and De Se. Philosophical Review, 88(4), 513-543.

Matushansky, O. and Ruys, E. (2007). "Same" in Russian. In Formal Semantics in Moscow 3.

Percus, O. (2000). Constraints on Some Other Variables in Syntax. Linguistics and 
Philosophy, 173-229.

Percus, O. and Sauerland, U. (2003). On the LFs of attitude reports. In Proceedings of Sinn und Bedeutung 7. Konstanz: Universität Konstanz.

Quine, W. V. (1956). Quantifiers and Propositional Attitudes. The Journal of Philosophy, 53(5), 177-187. https://doi.org/10.2307/2022451

Russell, B. (1905). On Denoting. Mind, (14), 479-493.

Schwager, M. (2011). Speaking of Qualities. In Proceedings of SALT (Vol. 19, pp. 395-412).

Sudo, Y. (2014). On De Re Predicates. In Proceedings of WCCFL (pp. 447-456).

Tiskin, D. (2016). Conditional Attitude Ascription. Epistemology \& Philosophy of Science, (4), 74-93. 